\title{
Land surface brightness temperature retrieved from Landsat data
}

\author{
$\underline{\text { F. Li }}^{\text {a }}$, D. L. B. Jupp ${ }^{\text {b }}$, M. Thankappan ${ }^{\text {a }}$ L-W. Wang ${ }^{\text {a }}$, J. Sixsmith ${ }^{\text {a }}$, A. Lewis a and A. Held ${ }^{\text {b }}$ \\ ${ }^{a}$ National Earth and Marine Observations Branch, Geoscience Australia, GPO Box 378, ACT, 2601, \\ Australia \\ ${ }^{b}$ CSIRO, Land and Water, GPO Box 3023, ACT 2601, Australia \\ Email: Fuqin.Li@ga.gov.au
}

\begin{abstract}
Land Surface Temperature $\left(\mathrm{T}_{\mathrm{s}}\right)$ is an important boundary condition in many land surface modelling schemes. It is also important in other application areas such as hydrology, urban environmental monitoring, agriculture, ecological and bushfire monitoring. Many studies have shown that it is possible to retrieve $T_{s}$ globally using thermal infrared data from satellites. Development of standard methodologies that routinely generate $T_{s}$ products would be of broad benefit to the utility of remote sensing data in applications such as hydrology and urban monitoring.
\end{abstract}

AVHRR and MODIS datasets are routinely used to deliver $T_{\mathrm{s}}$ products. However, these data have a $1 \mathrm{~km}$ spatial resolution, which is too coarse to detect the detailed variation of land surface change of concern in many applications, especially in heterogeneous areas. Higher resolution thermal data from Landsat (60-120 $\mathrm{m})$ is a possible option in such cases.

To derive $\mathrm{T}_{\mathrm{s}}$, two scientific problems need to be addressed, the first of which is the focus of this paper:

- Remove the atmospheric effects and derive surface brightness temperature $\left(T_{B}\right)$,

- Separate the emissivity and $T_{\mathrm{S}}$ effects in the surface brightness temperature $\left(T_{B}\right)$.

For single thermal band sensors such as Landsat 5, 7 and due to a stray-light issue on Landsat-8, the multiband methods used to derive $\mathrm{T}_{\mathrm{B}}$, such as the split window methods used for NOAA-AVHRR data (Becker \& $\mathrm{Li}, 1990$ ) and the day/night pairs of thermal infrared data in several bands used for MODIS (Wan et al., 2002) are not available for correcting atmospheric effects. The inputs used for retrieval of surface brightness temperature $T_{B}$ from Landsat data therefore need more attention, as the accuracy of the $T_{B}$ retrieval depends critically on the ancillary data, such as atmospheric water vapour data (precipitable water). In the past, it has been more difficult to retrieve a reliable $\mathrm{T}_{\mathrm{B}}$ product routinely from Landsat due to limited availability (time and space) of accurate atmospheric water vapour information.

To test the possibility for retrieving a good quality $T_{B}$ product routinely from Landsat, in this paper, $T_{B}$ products are derived from four current and routinely available global atmospheric profiles, namely the NASA Modern Era Retrospective-Analysis for Research and Applications (MERRA); the National Center for Environmental Prediction (NCEP) reanalysis I, the National Center for Environmental Prediction reanalysis II and the European Centre for Medium-Range Weather Forecasts (ECMWF) Interim reanalysis. These products were evaluated against the $\mathrm{T}_{\mathrm{B}}$ derived from the near coincident ground-released radiosonde data (balloon data) using a physically based radiative transfer model MODTRAN 5. The results from this comparison have found:

- The global data sets NCEP1, NCEP2, MERRA and ECMWF can all generally give satisfactory $T_{B}$ products and can meet the $1 \mathrm{~K}$ accuracy levels demanded by many practitioners.

- The ECMWF data set performs best. The root mean square difference (RMSD) for the 9 days and 3 test sites are all within $0.4 \mathrm{~K}$ when compared with the $\mathrm{T}_{\mathrm{B}}$ products estimated using ground-released radiosonde measurements.

The results show that using single thermal band Landsat, accurate $\mathrm{T}_{\mathrm{B}}$ can be delivered operationally using a robust physically based radiative transfer model such as MODTRAN 5 and operationally available global atmospheric profiles, particularly the ECMWF interim reanalysis data.

Keywords: $\quad$ Surface brightness temperature, Landsat, atmospheric correction, precipitable water 


\section{INTRODUCTION}

Land surface temperature $\left(\mathrm{T}_{\mathrm{s}}\right)$ is an important land surface parameter used in many applications such as land surface modelling and hydrology, urban environmental monitoring, agriculture and ecological monitoring as well as disaster management applications ( $\mathrm{Li}$, et al., 2013). Currently available satellite thermal infrared sensors provide a varying scale of spatial resolution and temporal coverage data that can be used to estimate land surface temperature. The coarser resolution sensors that currently provide thermal data include the 4-km resolution Geostationary Operational Environmental Satellite (GOES), the 2-km resolution Himawari 8, the $1-\mathrm{km}$ resolution NOAA-Advanced Very High Resolution Radiometer (AVHRR) and Terra and AquaModerate Resolution Imaging Spectroradiometer (MODIS). Although coarser resolution satellite data can provide daily $T_{s}$ globally, they cannot provide the detailed scale of information required for many applications, especially in heterogeneous areas. Higher resolution $\mathrm{T}_{\mathrm{s}}$ is needed for many applications, such as urban monitoring and hydrology. At present, higher resolution $\mathrm{T}_{\mathrm{s}}$ products are available from the $90 \mathrm{~m}$ resolution Terra-Advanced Spaceborne Thermal Emission and Reflection Radiometer (ASTER), the $120 \mathrm{~m}$ resolution Landsat-5 Thematic Mapper (TM), the $60 \mathrm{~m}$ resolution Landsat-7 Enhanced Thematic Mapper (ETM) and the $100 \mathrm{~m}$ resolution Landsat 8 Thermal Infrared Sensor (TIRS). To derive $\mathrm{T}_{\mathrm{s}}$, two scientific problems need to be resolved. (i) to remove the atmospheric effects and estimate surface brightness temperature $\left(\mathrm{T}_{\mathrm{B}}\right)$ (i.e., atmospheric correction); and (ii) to separate the emissivity $\left(\varepsilon_{\lambda}\right)$ and $\mathrm{T}_{\mathrm{s}}$ effects in the surface brightness temperature. In this paper, we focus solely on the first step.

For atmospheric correction using single band thermal sensors such as Landsat 5, 7 and 8 (Landsat 8 is treated as a single band sensor in this study since its second thermal band, band 11 , has a serious stray light issue which is yet to be resolved), multi-band split window methods, such as those used for NOAA-AVHRR data (Becker \& Li, 1990), and day/night pairs of thermal infrared data in several bands, as used for MODIS (Wan et al., 2002) are not available for correcting atmospheric effects. However, many studies have shown that if we have accurate ground-released radiosonde measurements (balloon data) taken to a sufficient altitude in the atmosphere, an accurate radiative transfer model (such as MODTRAN 5) can effectively remove most of the atmospheric effects. The accuracy of surface brightness temperature derived in this way has been found to be within $1 \mathrm{~K}$ (Li et al., 2004 and Jacob et al., 2004, Coll et al., 2012). The problem has been that groundreleased radiosonde measurements with sufficient spatial and temporal density are not generally available. For operational processing of Landsat data, other data sets are needed. Currently, several atmospheric reanalysis profiles from weather forecast and satellite data are available globally. Jimenze-Munoz et al. (2010) and Coll et al. (2012) found in their studies that these data sets were accurate enough to produce a good $T_{s}$ product in the rice fields of Spain. In this study, two products from NCEP, one product from MERRA and one product from ECMWF have been used to derive surface brightness temperature products using 9 thermal images from Landsat 5, 7 and 8 over three sites in Australia. The surface brightness temperature products from these global reanalysis products have been compared with those estimated using local radiosonde data (balloon data).

\section{METHODOLOGY}

The thermal radiation from a black body at wavelength $\lambda$ can be expressed using the Planck radiation formula:

$$
B_{\lambda}\left(T_{s}\right)=\frac{2 h c^{2}}{\lambda^{5}\left[\exp \left(\frac{h c}{\kappa \lambda T_{s}}\right)-1\right]},
$$

Where $h$ is Planck's constant, $c$ is the speed of light, $\kappa$ is Boltzman's constant and $B_{\lambda}$ is black body radiance. This equation may be inverted to provide an expression for temperature in terms of radiance. In this case it has the form (Schmugge et al., 1998):

$$
T_{s}=\frac{C_{2}}{\lambda \ln \left[C_{1} /\left(B_{\lambda} \lambda^{5} \pi\right)+1\right]},
$$

where $C_{1}$ and $C_{2}$ are constants., with values of $3.74151 \times 10^{-16}\left(\mathrm{Wm}^{2}\right)$ and $0.0143879(\mathrm{~m} \mathrm{~K})$ respectively.

The relationship between band radiance and surface temperature is more complex than for a single wavelength. For a given band, let $W(\lambda)$ represent the spectral response function and assume $\int_{0}^{\infty} W(\lambda) d \lambda=1$, then radiance corresponding to the band $\left(L_{w}\right)$ can be expressed as: 
$L_{w}=\int_{0}^{\infty} W(\lambda) L_{\lambda}[T] d \lambda$,

where $L_{\lambda}$ is the emitted radiance at wavelength $\lambda$ and temperature T. Among various approaches used in this case to provide a convenient and direct transformation from radiance to temperature, one is to approximate the relationship for a given wavelength band by a function with the same form as the monochromatic Planck function. For example, the relationship between surface temperature and band integrated surface $L_{w}$ can be approximated as:

$$
T_{s}=\frac{k_{2}}{\ln \left[k_{1} / L_{w}+1\right]},
$$

where, $T_{s}$ is surface temperature in Kelvin, $L_{w}$ is integrated band radiance $\left(\mathrm{Wm}^{-2} \mathrm{sr}^{-1} \mu \mathrm{m}^{-1}\right)$, and $k_{l}$ $\left(\mathrm{Wm}^{-2} \mathrm{sr}^{-1} \mu \mathrm{m}^{-} 1\right)$ and $k_{2}(\mathrm{~K})$ are calibration constants. The calibration constants are chosen to optimize the approximation for the specific band pass of the sensor and are therefore sensor specific, with $k_{l}$ and $k_{2}$ for Landsat 5, 7 and 8 listed in Table 1 (Chander et al., 2009).

Table 1. Calibration coefficients for Landsat 5,7 and 8

\begin{tabular}{|c|c|c|c|c|}
\hline \multirow{2}{*}{$\begin{array}{c}\text { Calibration } \\
\text { coefficients }\end{array}$} & Landsat5 & Landsat7 & \multicolumn{2}{|c|}{ Landsat8 } \\
\cline { 2 - 5 } & Band6 & Band6 & Band10 & Band11 \\
\hline $\mathrm{k}_{1}$ & 607.76 & 666.09 & 774.89 & 480.89 \\
\hline $\mathrm{k}_{2}$ & 1260.56 & 1282.71 & 1321.08 & 1201.24 \\
\hline
\end{tabular}

According to Schmugge et al. (1998) and Li et al. $(2004,2013)$, the sensor measured radiance $I_{\text {sensor }}$ for thermal band (wavelength $\left.>6 \mu \mathrm{m}\right)$ can be simplified as:

$I_{\text {sensor }}=t_{\lambda} I_{w}(0)+d_{\lambda}=a D N+b$,

where $t_{\lambda}$ is atmospheric transmittance, $d_{\lambda}$ is the spectral path radiance added by the atmosphere, $I_{w}(0)$ is the surface leaving radiance, $a$ and $b$ are sensor calibration coefficients and $D N$ is the image digital number. Applying equation (4) to $I_{w}(0)$ provides a standard product called the brightness temperature $\left(\mathrm{T}_{\mathrm{B}}\right)$.

The surface leaving radiance can also be expressed in terms of surface temperature and emissivity as:

$I_{w}(0)=\varepsilon_{\lambda} L_{w}+\left(1-\varepsilon_{\lambda}\right) I_{d \lambda}$,

In this equation, $\varepsilon_{\lambda}$ is the (wavelength dependent) surface emissivity; $I_{d \lambda}$ is the down-welling sky radiance due to the atmosphere. The surface temperature $\left(\mathrm{T}_{\mathrm{s}}\right)$ can be obtained by applying equation (4) to $L_{w}$. Using the MODTRAN atmospheric radiative transfer model (Berk et al., 2008), $t_{\lambda}, d_{\lambda}$, and $I_{d \lambda}$ can be obtained in a straightforward way using the known Landsat band spectral response functions and reliable atmospheric profile data. Thus, the brightness temperature can be obtained from equations (4) and (5) and if effective band emissivity is known, the surface temperature can be calculated from equations (4), (5) and (6). The accurate estimation of brightness temperature, which is the first step as well as a useful product in its own right, will be the focus of this study.

\section{DATA AND TEST SITES}

\subsection{Test sites}

Three test sites were selected for this study representing different climates and landscapes. All have local radiosonde data (meteorological stations) available and are located within the corresponding Landsat scene. The Darwin site $(12.40 \mathrm{~S}, 130.87 \mathrm{E})$ is located in a tropical area with a summer monsoon climate. The average annual precipitation is $1700 \mathrm{~mm}$ and it has distinct wet and dry seasons. The wet season is from November to April, during which time it is hot and humid. The dry season runs from May to October. However, even in the dry season, precipitable water in the atmosphere is still very high compared with other regions of Australia. The Moree site (29.50S, 149.83E) is located near the New South Wales and Queensland border. It is a normally dry inland area with average annual precipitation of $585 \mathrm{~mm}$. Humidity and precipitable water in the atmosphere is usually low in this region. Wollongong $(32.78 \mathrm{~S}, 151.82 \mathrm{E})$ has a moderate coastal maritime climate and its average annual precipitation is $1300 \mathrm{~mm}$. Rainfall is evenly spread throughout the year. 


\subsection{Data descriptions}

A total of 9 clear Landsat images were selected for this study. Each test site has three images, comprising one Landsat 5 image, one Landsat 7 image and a Landsat 8 image. The 9 images were orthorectified to The Universal Transverse Mercator (UTM) projection using the USGS Level 1 Product Generation System (LPGS) processing

Table 2. Landsat images used in the analysis (UTC is Coordinated Universal Time), ordered by sites, then by dates.

\begin{tabular}{|c|c|c|c|c|c|c|}
\hline \multirow{2}{*}{$\begin{array}{c}\text { Date } \\
(\mathrm{dd} / \mathrm{mm} / \text { year })\end{array}$} & \multirow{2}{*}{ Site } & \multirow{2}{*}{ Landsat } & \multirow{2}{*}{ Path/Row } & \multicolumn{3}{|c|}{ Scene centre information } \\
\cline { 5 - 7 } & & & & Time $(\mathrm{UTC})$ & Latitude $\left(^{\circ}\right)$ & Longitude $\left(^{\circ}\right)$ \\
\hline $02 / 05 / 2003$ & Darwin & 7 & $106 / 069$ & 1.20 & $13.01 \mathrm{~S}$ & $130.36 \mathrm{E}$ \\
\hline $07 / 05 / 2008$ & Darwin & 5 & $106 / 069$ & 1.20 & $13.01 \mathrm{~S}$ & $130.41 \mathrm{E}$ \\
\hline $08 / 05 / 2014$ & Darwin & 8 & $106 / 069$ & 1.38 & $13.02 \mathrm{~S}$ & $130.41 \mathrm{E}$ \\
\hline $06 / 10 / 2000$ & Moree & 7 & $091 / 080$ & 23.75 & $28.86 \mathrm{~S}$ & $149.80 \mathrm{E}$ \\
\hline $07 / 10 / 2009$ & Moree & 5 & $091 / 080$ & 23.75 & $28.87 \mathrm{~S}$ & $149.80 \mathrm{E}$ \\
\hline $02 / 10 / 2013$ & Moree & 8 & $091 / 080$ & 23.95 & $28.85 \mathrm{~S}$ & $149.86 \mathrm{E}$ \\
\hline $12 / 09 / 2002$ & Wollongong & 7 & $089 / 083$ & 23.53 & $33.18 \mathrm{~S}$ & $151.76 \mathrm{E}$ \\
\hline $13 / 09 / 2011$ & Wollongong & 5 & $089 / 083$ & 23.54 & $33.19 \mathrm{~S}$ & $151.79 \mathrm{E}$ \\
\hline $18 / 09 / 2013$ & Wollongong & 8 & $089 / 083$ & 23.76 & $33.18 \mathrm{~S}$ & $151.79 \mathrm{E}$ \\
\hline
\end{tabular}

system implemented at Geoscience Australia (GA). Details information about the Landsat data used are listed in Table 2.

Five radiosonde data sets were used for this study. The data included the local radiosonde from Australian Bureau of Meteorology (balloon data, downloaded from the NOAA website: http://www.esrl.noaa.gov/raobs/); the NCEP reanalysis I (NECP1) (Kalnay et al., 1996), NCEP reanalysis II (NCEP2) (Kanamitsu et al., 2002), the MERRA reanalysis data (Rienecker, et al., 2011) and ECMWF interim reanalysis data (Dee et al., 2011). For detailed information about each data set see the references listed above and also http://reanalyses.org/atmosphere/overview-current-reanalyses. Since the Landsat overpass in Australia is usually close to 0 UTC (Table 2), the 0 UTC data for the five radiosonde data were used in this study. Table 3 lists the detailed information of the five radiosonde data sets used. NECP1 data are available from 1948

Table 3. Details information for the five radiosonde data used in the study.

\begin{tabular}{|l|l|c|c|c|c|c|}
\hline & \multicolumn{2}{|c|}{ Highest resolution } & \multicolumn{2}{c|}{ Number of vertical layers } & \multicolumn{2}{c|}{ Top layer pressure (mb) } \\
\hline & Spatial $\left({ }^{\circ}\right)$ & Temporal (hours) & Temperature & Humidity & Temperature & Humidity \\
\hline Balloon & irregular & 12 & irregular & irregular & $10-30$ & $10-30$ \\
\hline NECP1 & 2.5 & 6 & 17 & 8 & 10 & 300 \\
\hline NECP2 & 2.5 & 6 & 17 & 17 & 10 & 10 \\
\hline MERRA & 1.25 & 3 & 42 & 42 & 0.1 & 0.1 \\
\hline ECMWF & 0.125 & 6 & 37 & 37 & 1 & 1 \\
\hline
\end{tabular}

To ensure accuracy for thermal data correction, MODTRAN needs atmospheric profiles with all the parameters available up to $30-40 \mathrm{~km}$ altitude (around $10 \mathrm{mb}$ ). The NCEP1 data set is the only one among the data sets used here that does not meet these requirements. In such a situation, the default MODTRAN atmospheric profiles are generally used for the upper layers.

Most of the reanalysis data are presented relative to atmospheric pressure. The lowest layer is at $1000 \mathrm{mb}$ which is nominally sea level. However, in some areas, the actual surface pressure is lower than $1000 \mathrm{mb}$ and in others, surface pressure is higher than $1000 \mathrm{mb}$. So, an extra surface layer is needed if these data are used for MODTRAN runs. In addition, Jacob et al. (2004) found that if routine surface meteorological data, such as surface air temperature, relative humidity and atmospheric pressure are used for the first layer of the atmospheric profile, the accuracy of atmospheric correction improves. Based on their findings, here, the first layer of the atmospheric profile used ground measurements.

Precipitable water is critical for applying atmospheric correction to the thermal data (Li et al., 2004, Jacob et al., 2004). Other input data, such as aerosol optical depth and ozone data that are needed for the thermal data correction were consistent with those used for the surface reflectance atmospheric correction processing performed in Geoscience Australia (Li et al., 2010). 


\section{RESULTS}

The 9 images were processed using the methods described in section 2 with the five different atmospheric profiles. The accumulated precipitable water from the five different atmospheric profiles is listed in Table 4. In general, the results from using the global products are close to those based on the balloon data. ECMWF gave the closest results, especially for Darwin site where other data sets gave poor results.

The MODTRAN 5 output $t_{\lambda}, d_{\lambda}$ and $I_{d \lambda}$ used to compute surface brightness temperature are listed in Table 5 for the five different atmospheric profiles (center point of the image only).
Table 4. Precipitable water $\left(\mathrm{g} \mathrm{cm}^{-2}\right)$ data calculated from the five different profiles, the first letter indicates the site location.

\begin{tabular}{|c|c|c|c|c|c|}
\hline $\begin{array}{c}\text { Site: Date } \\
\text { (dd/mm/year })\end{array}$ & Balloon & MERRA & NCEP1 & NCEP2 & ECMWF \\
\hline D: $02 / 05 / 2003$ & 2.93 & 3.66 & 3.17 & 3.73 & 3.04 \\
\hline D: $07 / 05 / 2008$ & 1.63 & 1.80 & 1.97 & 1.80 & 1.77 \\
\hline D: $08 / 05 / 2014$ & 2.96 & 3.47 & 3.28 & 3.30 & 3.09 \\
\hline M: 06/10/2000 & 1.28 & 1.23 & 1.17 & 1.07 & 1.27 \\
\hline M: 07/10/2009 & 0.58 & 0.75 & 0.84 & 0.77 & 0.64 \\
\hline M: 02/10/2013 & 0.90 & 0.83 & 0.81 & 0.84 & 0.83 \\
\hline W: $12 / 09 / 2002$ & 1.00 & 1.17 & 1.15 & 1.17 & 1.13 \\
\hline W: $13 / 09 / 2011$ & 0.61 & 0.68 & 0.72 & 0.83 & 0.82 \\
\hline W: $18 / 09 / 2013$ & 0.89 & 0.80 & 1.11 & 1.10 & 0.98 \\
\hline
\end{tabular}

Table 5. MODTRAN output $t_{\lambda}, d_{\lambda}$ and $I_{d \lambda}\left(\mathrm{Wm}^{-2} \mathrm{sr}^{-1} \mu \mathrm{m}^{-1}\right)$ from the five profiles (centre point of the image). Note: for Landsat 8, only band 10 is included in the assessment, the first letter indicates the site location. RMSD is relative to the Balloon data.

\begin{tabular}{|c|c|c|c|c|c|c|c|c|c|c|c|c|c|c|c|}
\hline \multirow{2}{*}{$\begin{array}{c}\text { Site: Date } \\
\text { (dd/mm/year) }\end{array}$} & \multicolumn{3}{|c|}{ Balloon } & \multicolumn{3}{|c|}{ MERRA } & \multicolumn{3}{|c|}{ NCEP1 } & \multicolumn{3}{|c|}{ NCEP2 } & \multicolumn{3}{|c|}{ ECMWF } \\
\hline & $t_{\lambda}$ & $\overline{d_{\lambda}}$ & $\mathrm{I}_{\mathrm{d} \lambda}$ & $t_{\lambda}$ & $\overline{d_{\lambda}}$ & $\mathrm{I}_{\mathrm{d} \lambda}$ & $\mathrm{t}_{\lambda}$ & $\mathrm{d}_{\lambda}$ & $\mathrm{I}_{\mathrm{d} \lambda}$ & $\mathrm{t}_{\lambda}$ & $\mathrm{d}_{\lambda}$ & $\mathrm{I}_{\mathrm{d} \lambda}$ & $\mathrm{t}_{\lambda}$ & $\mathrm{d}_{\lambda}$ & $\mathrm{I}_{\mathrm{d} \lambda}$ \\
\hline D: $02 / 05 / 2003$ & 0.652 & 2.89 & 4.47 & 0.550 & 3.69 & 5.55 & 0.599 & 3.35 & 5.10 & 0.513 & 4.02 & 5.94 & 0.628 & 3.12 & 4.78 \\
\hline D: 07/05/2008 & 0.811 & 1.51 & 2.42 & 0.763 & 1.91 & 3.02 & 0.739 & 2.11 & 3.33 & 0.765 & 1.89 & 2.99 & 0.790 & 1.68 & 2.68 \\
\hline D: 08/05/2014 & 0.652 & 2.82 & 4.41 & 0.577 & 3.46 & 5.24 & 0.619 & 3.19 & 4.90 & 0.605 & 3.31 & 5.05 & 0.653 & 2.85 & 4.44 \\
\hline M: 06/10/2000 & 0.833 & 1.32 & 2.12 & 0.842 & 1.28 & 2.06 & 0.850 & 1.21 & 1.96 & 0.865 & 1.08 & 1.75 & 0.835 & 1.33 & 2.14 \\
\hline M: 07/10/2009 & 0.923 & 0.50 & 0.83 & 0.903 & 0.64 & 1.06 & 0.888 & 0.77 & 1.28 & 0.907 & 0.59 & 0.98 & 0.919 & 0.54 & 0.89 \\
\hline M: 02/10/2013 & 0.896 & 0.72 & 1.21 & 0.910 & 0.62 & 1.04 & 0.910 & 0.61 & 1.03 & 0.913 & 0.59 & 1.00 & 0.905 & 0.66 & 1.12 \\
\hline $\mathrm{W}: 12 / 09 / 2002$ & 0.866 & 0.93 & 1.52 & 0.847 & 1.07 & 1.74 & 0.841 & 1.12 & 1.82 & 0.840 & 1.13 & 1.84 & 0.851 & 1.05 & 1.71 \\
\hline W: 13/09/2011 & 0.919 & 0.57 & 0.94 & 0.917 & 0.58 & 0.95 & 0.898 & 0.74 & 1.21 & 0.894 & 0.76 & 1.23 & 0.890 & 0.75 & 1.23 \\
\hline W: 18/09/2013 & 0.896 & 0.73 & 1.22 & 0.916 & 0.58 & 0.99 & 0.865 & 0.98 & 1.64 & 0.881 & 0.86 & 1.43 & 0.888 & 0.80 & 1.33 \\
\hline RMSD & N/A & N/A & N/A & 0.047 & 0.38 & 0.52 & 0.038 & 0.32 & 0.48 & 0.055 & 0.45 & 0.61 & 0.016 & 0.12 & 0.19 \\
\hline
\end{tabular}

From Tables $4 \& 5$, we can conclude that the precipitable water (as expected) strongly impacts on the atmospheric parameters (path radiance $\mathrm{d}_{\lambda}$, transmittance $\mathrm{t}_{\lambda}$ and downwelling radiation $\mathrm{I}_{\mathrm{d} \lambda}$ ). RMSD in Table 5 shows that ECMWF gave least RMSD for all parameters. The surface brightness temperature products can be computed using equations (4), (5). In this study, 9 days of surface brightness temperature have been generated. Due to page limits, only a subset of the $T_{B}$ images of Landsat 7 for May 2, 2003 at Darwin site (path 106, row 69, subset center 12.855S, 130.945E) have been displayed in Figure 1. Table 5 shows that MODTRAN output has greatest discrepancy between the balloon data and NCEP2 and MERRA.
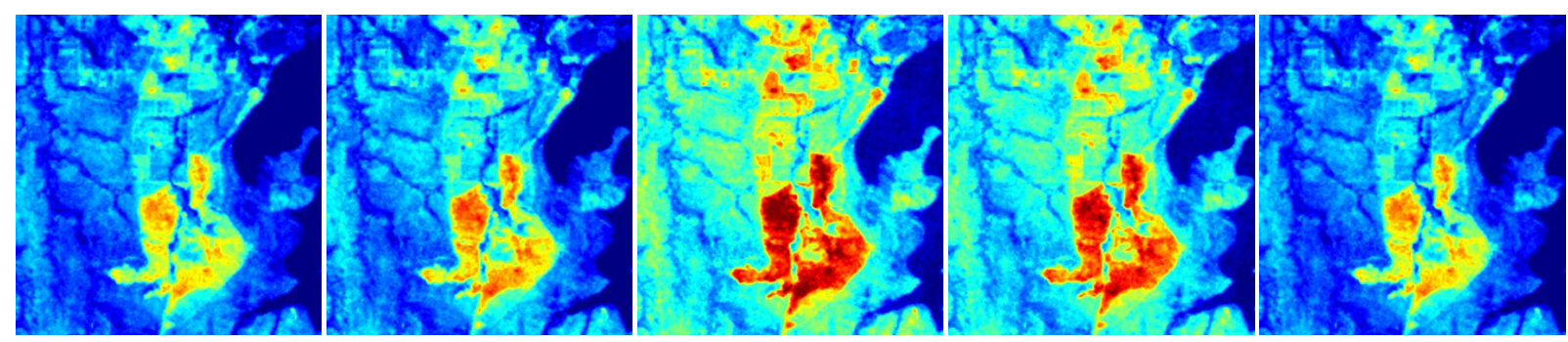

$\begin{array}{lllll}300 & 305 & 310 & 315 & 320\end{array}$

(K)

Figure 1. $\mathrm{T}_{\mathrm{B}}\left({ }^{\mathrm{O}} \mathrm{K}\right)$ image of Landsat 7 image on May 2, 2003, from left to right, using balloon data; using NCEP1, using NCEP2, using MERRA and using ECMWF. 
Figure 1 shows that there is not much difference between the images produced from balloon and ECMWF $(<0.3 \mathrm{~K})$. However, using NCEP2 and MERRA data, $\mathrm{T}_{\mathrm{B}}$ is several degrees higher than those corrected using the balloon data. To quantitatively analyse the impact of different atmospheric profiles on the atmospheric correction accuracy for all images, five surface brightness temperature images of 9 days were compared. Assuming that the balloon data to be accurate, the $\mathrm{T}_{\mathrm{B}}$ products corrected using balloon data can then be regarded as the ground truth. The differences can then be calculated between the surface brightness temperature derived from the balloon data and the MERRA, NCEP $1 \& 2$ and ECMWF data.

Table 6 shows how the different atmospheric profiles impact the overall results for surface brightness temperature retrieval. The results show that for the Moree and Wollongong sites, where the selected days are relatively dry, reanalysis atmospheric profiles are all close to the balloon data. The root mean square difference (RMSD) falls within $1 \mathrm{~K}$ using all data sets. Both MERRA and ECMWF provide good agreement, especially ECMWF. ECMWF also gave good agreement with Darwin site where MERRA and NCEP2 performed badly. Large RMSD values occur at the Darwin site when MERRA and NCEP2 were used. May 2, 2003 has the highest RMSD for MERRA and NCEP2 data sets with RMSD being larger than $2 \mathrm{~K}$ for MERRA and $3 \mathrm{~K}$ for NCEP2, respectively. Overall, ECMWF gave consistent results for all the three sites with RMSD being within $0.4 \mathrm{~K}$ for all of the 9 days.

Table 6. Surface brightness temperature difference between the outputs from MERRA, NCEP1\& 2, ECMWF and that from ground based radiosonde data. Where Min and Max are the minimum and maximum difference in the image, respectively. RMSD is root mean square difference in the image, all values are $\mathrm{K}$, the first letter indicates the site location.

\begin{tabular}{|c|c|c|c|c|c|c|c|c|c|c|c|c|c|}
\hline \multirow{2}{*}{$\begin{array}{c}\text { Site: Date } \\
\text { dd/mm/year }\end{array}$} & \multicolumn{3}{|c|}{ MERRA } & \multicolumn{3}{|c|}{ NCEP1 } & \multicolumn{3}{|c|}{ NCEP2 } & \multicolumn{3}{|c|}{ ECMWF } \\
\cline { 2 - 12 } & Min & Max & RMSD & Min & Max & RMSD & Min & Max & RMSD & Min & Max & RMSD \\
\hline D: $02 / 05 / 2003$ & -9.72 & 0.40 & 2.534 & -4.28 & 0.89 & 0.646 & -13.7 & 1.27 & 3.140 & -1.67 & 0.65 & 0.117 \\
\hline D: $07 / 05 / 2008$ & -1.50 & 1.34 & 0.556 & -2.35 & 2.00 & 0.876 & -1.40 & 1.32 & 0.500 & -0.66 & 0.54 & 0.265 \\
\hline D: 08/05/2014 & -4.56 & -0.43 & 1.477 & -1.19 & 0.78 & 0.319 & -2.04 & 0.72 & 0.206 & 0.30 & 0.39 & 0.363 \\
\hline M: 06/10/2000 & 0.26 & 0.57 & 0.445 & 0.27 & 0.92 & 0.663 & 0.14 & 1.42 & 0.924 & 0.17 & 0.19 & 0.182 \\
\hline M: $07 / 10 / 2009$ & -0.71 & 0.18 & 0.463 & -1.08 & 0.57 & 0.622 & -0.72 & -0.07 & 0.537 & -0.15 & 0.06 & 0.088 \\
\hline M: 02/10/2013 & -0.12 & 0.38 & 0.241 & -0.17 & 0.33 & 0.196 & -0.19 & 0.40 & 0.240 & 0.00 & 0.31 & 0.221 \\
\hline W: $12 / 09 / 2002$ & -0.90 & 0.25 & 0.156 & -1.20 & 0.36 & 0.197 & -1.24 & 0.40 & 0.190 & -0.64 & 0.29 & 0.057 \\
\hline W: $13 / 09 / 2011$ & -0.09 & -0.02 & 0.056 & -0.39 & 0.44 & 0.051 & -0.58 & 0.36 & 0.155 & -0.54 & 0.37 & 0.127 \\
\hline W: $18 / 09 / 2013$ & -0.19 & 0.51 & 0.239 & -0.52 & 0.70 & 0.093 & -0.24 & 0.38 & 0.042 & -0.16 & 0.17 & 0.036 \\
\hline
\end{tabular}

\section{DISCUSSIONS AND CONCLUSIONS}

Many past studies have shown that with reliable ancillary data and adequate atmospheric modelling software, it is possible to accurately estimate surface brightness temperature from remotely sensed data. This includes the higher spatial resolution data available from Landsat. For such single thermal band instruments, the critical data needed for atmospheric correction are accurate atmospheric water vapour profiles.

The results from this study have shown that for the atmospheric correction step of the process, the global data sets NCEP1, NCEP2, MERRA and ECMWF can generally give satisfactory results and can meet the levels of accuracy demanded by many practitioners, such as $1 \mathrm{~K}$ for surface brightness temperature. Among the data sets we used, ECMWF gave excellent results with RMSD all falling within $0.4 \mathrm{~K}$ in all the test data. The ECMWF data set also has relatively high spatial resolution $\left(0.125^{\circ} \times 0.125^{\circ}\right)$ and 37 vertical layers (up to $1 \mathrm{mb}$ of pressure). It therefore meets operational requirements. Recently, ECMWF data have also become more easily accessed and freely available to download. This makes the operational processing of thermal data feasible at least to an accurate and operational brightness temperature.

The present study has only focused on relatively flat areas. Additional correction may be needed if surface temperature data from rugged areas are needed (see Liu et al., 2006). A research study may also be needed to establish this for the terrain encountered in Australia and if needed, the methods described by Liu et al. (2006) could be implemented using the established framework of the DEM based processing currently implemented at GA for the reflective bands. Accurate emissivity estimation is also a crucial step to derive reliable land surface temperature. The approach needed for derivation of an effective emissivity product and associated surface temperature will be the subject of a future study. 


\section{ACKNOWLEDGMENTS}

This paper is published with the permission of the CEO, Geoscience Australia (GA) and the permission of CSIRO. The data used are all available for operational processing. The ground-released radiosonde data were downloaded from: http://www.esrl.noaa.gov/raobs/. NCEP1 and NCEP2 data were downloaded from: ftp://ftp.cdc.noaa.gov/. MERRA data were downloaded from: http://disc.sci.gsfc.nasa.gov/daacbin/DataHoldings.pl. ECMWF is downloaded from: http://apps.ecmwf.int/datasets/data/interim-full-daily/. The Landsat images were provided by GA. Norman Mueller and Stephen Sagar from GA and Tim McVicar from CSIRO reviewed the early draft of the paper. Anonymous reviewers and editor provided many constructive comments and valuable suggestions that significantly improved the paper.

\section{REFERENCES}

Becker, F. and Li, Z. (1990). Towards a local split window method over land surfaces. International Journal of Remote Sensing, 11, 369-393.

Berk, A., Anderson, G.P., Acharya, P.K. and Shettle, E.P. (2008). MODTRAN5.2.0.0 user's manual. Spectral Science Inc., Burlington MA, Air Force Research Laboratory, Hanscom MA, and Naval Research Laboratory, Washington DC.

Chander, G., Markham, B.L. and Helder, D.L. (2009). Summary of current radiometric calibration coefficients for Landsat MSS, TM, ETM+, and EO-1 ALI sensors. Remote Sensing of Environment, 113, 893-903.

Coll, C., Caselles, V., Valor, E., \& Niclòs, R. (2012). Comparison between different sources of atmospheric profiles for land surface temperature retrieval from single channel thermal infrared data. Remote Sensing of Environment, 117, 199-210.

Dee, D. P. and 35 co-authors (2011). The ERA-Interim reanalysis: Configuration and performance of the data assimilation system. Quarterly Journal of the Royal Meteorology Society, 137, 553-597.

Jacob, F., Petitcolin, F., Schmugge, T., Vermote, E., French, A. \& Ogawa, K. (2004). Comparison of land surface emissivity and radiometric temperature derived from MODIS and ASTER sensors. Remote Sensing of Environment, 90, 137-152.

Jiménez-Muñoz, J., Sobrino, J., Mattar, C., \& Franch, B. (2010). Atmospheric correction of optical imagery from MODIS and Reanalysis atmospheric products. Remote Sensing of Environment, 114, 2195-2210.

Kalnay, E. and 21 coauthors (1996). The NCEP/NCAR 40-year reanalysis project, Bulletin American Meteorology Society, 77, 437-471

Kanamitsu, M., Ebisuzaki, W., Woollen, J., Yang, S. Hnilo, J.J., Fiorino, M. and Potter, G.L. (2002). NCEPDOE AMIP-II Reanalysis (R-2). Bulletin American Meteorology Society, 83, 1631-1643.

Li, F., Jackson, T.J., Kustas, W.P., Schmugge, T.J., French, A.N., Cosh, M.H and Bindlish, R. (2004). Deriving land surface temperature from Landsat 5 and 7 during SMEX02/SMACEX, Remote Sensing of Environment, 92, 521-534.

Li, F., Jupp, D.L.B., Reddy, S., Lymburner, L., Mueller, N., Tan, P. and Islam, A. (2010). An Evaluation of the Use of Atmospheric and BRDF Correction to Standardize Landsat Data. IEEE Journal of Selected Topics in Applied Earth Observations and Remote Sensing, 3: 257 - 270

Li, Z., Tang, B., Wu, H., Ren, H., Yan, G., Wan, Z., Trigo, I. and Sobrino, J. (2013). Satellite-derived land surface temperature: Current status and perspectives. Remote Sensing of Environment, 131, 14-37

Liu, Y., Hiyama, T. \& Yamaguchi, Y. (2006). Scaling of land surface temperature using satellite data: A case examination on ASTER and MODIS products over a heterogeneous terrain area. Remote Sensing of Environment, 105,115-128.

Rienecker, and 28 coauthors (2011), MERRA: NASA's Modern-Era Retrospective Analysis for Research and Applications. Journal of Climate, 24, 3624-3648.

Schmugge, T., Hook, S.J. \& Coll, C. (1998). Recovering surface temperature and emissivity from thermal infrared multispectral data. Remote Sensing of Environment, 65, 121-131.

Wan, Z., Zhang, Y., Zhang, Q. \& Li, Z. (2002). Validation of the land surface temperature products retrieved from Terra Moderate Resolution Imaging Spectroradiometer data. Remote Sensing of Environment, 83, $163-180$. 